\title{
Ideal Time of Day for Risky Decision Making: Evidence from the Balloon Analogue Risk Task
}

This article was published in the following Dove Press journal:

Nature and Science of Sleep

\section{Mingzhu $\mathrm{Li}^{1-5}$ \\ Zifeng Mai ${ }^{1-5}$ \\ Jiayu Yang ${ }^{1-5}$ \\ Bin Zhang $\mathbb{D}^{6}$ \\ Ning $\mathrm{Ma} \mathbb{D}^{1-5}$}

'Key Laboratory of Brain, Cognition and Education Sciences (South China Normal University), Ministry of Education, Guangzhou 5I063I, People's Republic of China; ${ }^{2}$ School of Psychology, South China Normal University, Guangzhou 5 1063I, People's Republic of China; ${ }^{3}$ Center for Sleep Research, South China Normal University, Guangzhou 51063I, People's Republic of China; ${ }^{4}$ Center for Studies of Psychological Application, South China Normal University, Guangzhou 5I063I, People's Republic of China; ${ }^{5}$ Guangdong Key Laboratory of Mental Health and Cognitive Science, South China Normal University, Guangzhou 51063I, People's Republic of China; ${ }^{6}$ Department of Psychiatry, Nanfang Hospital, Southern Medical University, Guangdong-Hong KongMacao Greater Bay Area Center for Brain Science and Brain-Inspired Intelligence, Guangzhou 5/05/5, People's Republic of China
Correspondence: Ning Ma Center for Sleep Research,Center for Studies of Psychological Application, Guangdong Key Laboratory of Mental Health \& Cognitive Science, School of Psychology, South China Normal University, Guangzhou 5I063I, People's Republic of China

Email maning@m.scnu.edu.cn
Background: Previous studies have demonstrated that individuals showed higher risk preference in the afternoon than in the morning. However, few studies aimed to explore the alteration of feedback learning effect during risky decision making, which is one of the important psychological processes of real risk behaviors. Moreover, cognitive function altered at the off-peak time due to impaired inhibitory control. The present study is to investigate the time-of-day effect on risky decision making and inhibitory control and whether the alteration of inhibitory control causes the differences in risky decision making across one day.

Participants and Methods: We adopted a within-participants design without extremely chronotype individuals to measure the time-of-day ( 9 am vs $3 \mathrm{pm}$ ) effect on risky decision making by using the Balloon Analogue Risk Task. At the same time, we measured the inhibitory control by using the Go/no-go task.

Results: Our results confirmed that individuals showed higher risk preference in the afternoon than in the morning. In addition, we found that individuals were insensitive to loss and the previous negative feedback in the afternoon. Critically, the results did not reveal any significant correlation between risky decision making and inhibitory control under the regulation of the time-of-day effects, although individuals performed worse on inhibitory control in the afternoon.

Conclusion: The current findings revealed that the time-of-day effect regulated risky decision making and inhibitory control. Individuals act with higher risk preference, less sensitivity to loss as negative feedback, and lower inhibitory control in the afternoon than in the morning. This may reflect the effects of time-of-day on risk propensity and inhibitory control is relatively independent.

Keywords: time-of-day effect, risky decision making, inhibitory control

\section{Introduction}

Under the influence of the sleep-wake regulation, the human psychological and physiological functions fluctuate with the time in one day, ${ }^{1-4}$ which refers to timeof-day effect. This effect has been observed in many cognitive domains, including attention, working memory, inhibition control, as well as risky decision making. Byrne and Murray found that people typically exhibit a higher risk propensity in the afternoon; for example, in a study applied the Balloon Analogue Risk Task (BART), participants pumped more in the afternoon than in the morning and evening. ${ }^{5}$ Similarly, larks chronotype individuals distinguished by clock-related genes (PER3, NR1D2) have been found to be more adventurous in the afternoon than in the morning. ${ }^{6}$ 
Previous research about the time-of-day effect has primarily focused on risk preference. However, risky decision making is a complex behavior. The reinforcement sensitivity theory (RST) posits that the likelihood of risky behavior is affected by the sensitivity to reward (positive feedback) and punishment (negative feedback), and such feedback may differentially affect the subsequent decision. ${ }^{7,8}$ Individuals tend to become more conservative when a previous decision caused loss during risk-taking. ${ }^{9}$ People may adjust a current decision according to the outcome of the previous choice, which is known as the feedback learning effect of risk-taking. ${ }^{7,9}$ However, no research has explored the effect of time-of-day on feedback learning effect during risk-taking.

Inhibitory control is one of the core executive functions, which assists people to resist the distraction or lure of irrelevant information. ${ }^{10}$ Yoon and colleagues proposed that cognitive function altered between peak time and off-peak time and optimal functioning occurring at peak relative to offpeak times, which may be due to impaired inhibitory control. ${ }^{11}$ Individuals with impaired inhibitory control at offpeak time were difficult or unable to resist the distraction of irrelevant information, which cause undesirable or inappropriate responses. In line with this perspective, Kouchaki and Smith observed that compared to the morning, individuals acted more unethically in the afternoon when selfcontrol (one core aspect of inhibitory control) was too low to resist the temptation to perform unethical but self-profiting behavior. ${ }^{12}$ Similar results were observed in the study of the time-of-day effect on implicit memory and problemsolving. ${ }^{13,14}$ Furthermore, other studies revealed that a higher risk tendency was associated with impaired inhibitory control. ${ }^{15-18}$ Therefore, it is reasonable to speculate that the alteration of risky decision making was modulated by the impaired inhibitory control in the afternoon, because people may find it relatively difficult to resist the impulsivity associated with gain or reward.

The present study is aimed to explore the effect of time-of-day on risky decision making, as well as the feedback learning effect of risk decision-making, and to examine the potential relationship between risk-taking and inhibition control under the regulation of time-of-day effect. We used the Balloon Analogue Risk Task (BART) to measure the risk-taking. ${ }^{7,19,20}$ The BART provided multiple indexes to assess the risky decision making, not only the risk preference but also the feedback learning effect of learning during risk-taking. In detail, the number of balloon pumps in non-exploded balloons and the number of explosions reflect the risk preference, total gains reflect the performance of task, and the average number of pumps after exploded balloons or unexploded balloons (win or loss) reflect the feedback learning effects. ${ }^{7,21}$ Meanwhile, we used the Go/no-go task (GNG) to measure the performance of inhibitory control. ${ }^{22,23}$ The Go/no-go task required individuals to inhibit the prepotent response when the target stimulus appears, which widely applied to measure the inhibitory control function. ${ }^{11}$ Importantly, because of the interaction effect of chronotypes and timeof-day on risky behavior, ${ }^{6}$ we recruited individuals neither an extreme morning type nor an extreme evening type and adopted a within-participants design to avoid the potential confounding influence of individual differences.

Based on the previous studies, the hypotheses of the present study were as follows. First, we posited that risky decision making and inhibitory control fluctuated across a day. Individuals showed higher risk propensity and lower inhibitory control in the afternoon compared to in the morning. Second, the change of risky decision making during a day might be related to the alteration of inhibitory control.

\section{Participants and Methods Participants}

Twenty-eight participants (11 males, aged from 18 to 28 years, BMI from 16.53 to 23.37) were included in the study. All participates were right-handed and normal or corrected-tonormal vision. They were assessed by a structural screening questionnaire, consisting with a series of questions about their demographic information, sleep, and health history. The questions included (1) age and gender, (2) left or right-handed, (3) height and weight, (4) normal sleep hours and duration during weekdays and weekends, (5) habits of smoking, alcohol, and caffeine intake, (6) history of shift work and trans-meridian travel, and (7) history of physical, psychiatric, and sleeprelated disorders. All participants in the current study reported having no history of physical, psychiatric, and sleep-related disorders. They were non-smokers and were not addicted to caffeine or alcohol. They could not have shift work, transmeridian travel within the three months preceding the experiment. They were required to keep habitually good sleep, such as falling asleep no later than 12:00 am at the midnight, waking up no later than 8:00 am, and regularly having 7-9 hours of sleep every night for 2 weeks preceding the study, as verified by sleep diaries (mean sleep duration of all the participants was $7.93 \pm 0.38$ hours/day, for detail, see Table 1 ). They were also instructed not to consume any beverages or foods with 
Table I The Averaging Results of Sleep Dairy from Two Weeks Preceding the Study

\begin{tabular}{|c|c|c|c|c|c|c|c|}
\hline & Day I & Day 2 & Day 3 & Day 4 & Day 5 & Day 6 & Day7 \\
\hline Sleeping time & $23: 54 \pm 0.39$ & $23: 52 \pm 0.39$ & $23: 54 \pm 0.33$ & $23.46 \pm 0.43$ & $23: 45 \pm 0.33$ & $23: 48 \pm 0.40$ & $23: 50 \pm 0.36$ \\
\hline Waking time & $7: 46 \pm 0.64$ & $7: 48 \pm 0.62$ & $7: 44 \pm 0.61$ & $7: 45 \pm 0.60$ & $7: 50 \pm 0.57$ & $7: 45 \pm 0.56$ & $7: 46 \pm 0.50$ \\
\hline \multirow[t]{2}{*}{ Sleep duration (h) } & $7.87 \pm 0.55$ & $7.93 \pm 0.51$ & $7.85 \pm 0.59$ & $7.98 \pm 0.54$ & $8.07 \pm 0.57$ & $7.96 \pm 0.57$ & $7.93 \pm 0.45$ \\
\hline & Day 8 & Day 9 & Day 10 & Day II & Day 12 & Day 13 & Day 14 \\
\hline Sleeping time & $23: 53 \pm 0.37$ & $23: 54 \pm 0.39$ & $23: 49 \pm 0.40$ & $23: 53 \pm 0.44$ & $23: 49 \pm 0.38$ & $23: 49 \pm 0.46$ & $23: 49 \pm 0.36$ \\
\hline Waking time & $7: 51 \pm 0.52$ & $7: 47 \pm 0.50$ & $7: 45 \pm 0.51$ & $7: 49 \pm 0.50$ & $7: 52 \pm 0.52$ & $7: 38 \pm 0.44$ & $7: 43 \pm 0.51$ \\
\hline Sleep duration $(\mathrm{h})$ & $7.96 \pm 0.57$ & $7.88 \pm 0.47$ & $7.92 \pm 0.51$ & $7.93 \pm 0.52$ & $8.05 \pm 0.47$ & $7.83 \pm 0.52$ & $7.90 \pm 0.38$ \\
\hline
\end{tabular}

Note: Mean \pm SD

caffeine such as coffee and tea, within 48 hours prior to the experiment. The study was conducted in accordance with the international ethical standards for biological rhythm research ${ }^{24}$ and the Declaration of Helsinki (BMJ 1991; 302: 1194). This study was approved by the Medical Ethical Committee of the South China Normal University (of the principal investigator N.M.). Each participant provided written informed consent, they were paid certain money after finishing the study.

To measure individuals' chronotype, we used the Morningness-Eveningness Questionnaire (MEQ). ${ }^{25}$ Extreme morning type and evening type individuals were excluded. The scores of the participants in the present study were controlled between 30 and $70 .^{25,26}$

\section{Materials}

\section{Balloon Analogue Risk Task (BART)}

To measure risk-taking behavior, the BART was used. ${ }^{20} \mathrm{In}$ this task, participants were instructed to inflate a balloon on the screen by pressing the button of "pump" to inflate a balloon or pressing the button of "collect" to stop and collect money. The balloon gets bigger, more points will be collected. But the possibility of the explosion would be higher as pumping more times. Participants can collect the coins of the balloon before the explosion, and lose the coins if balloon bursts. After the experiment, total gains would be converted into cash and paid to the participants (see Figure 1).

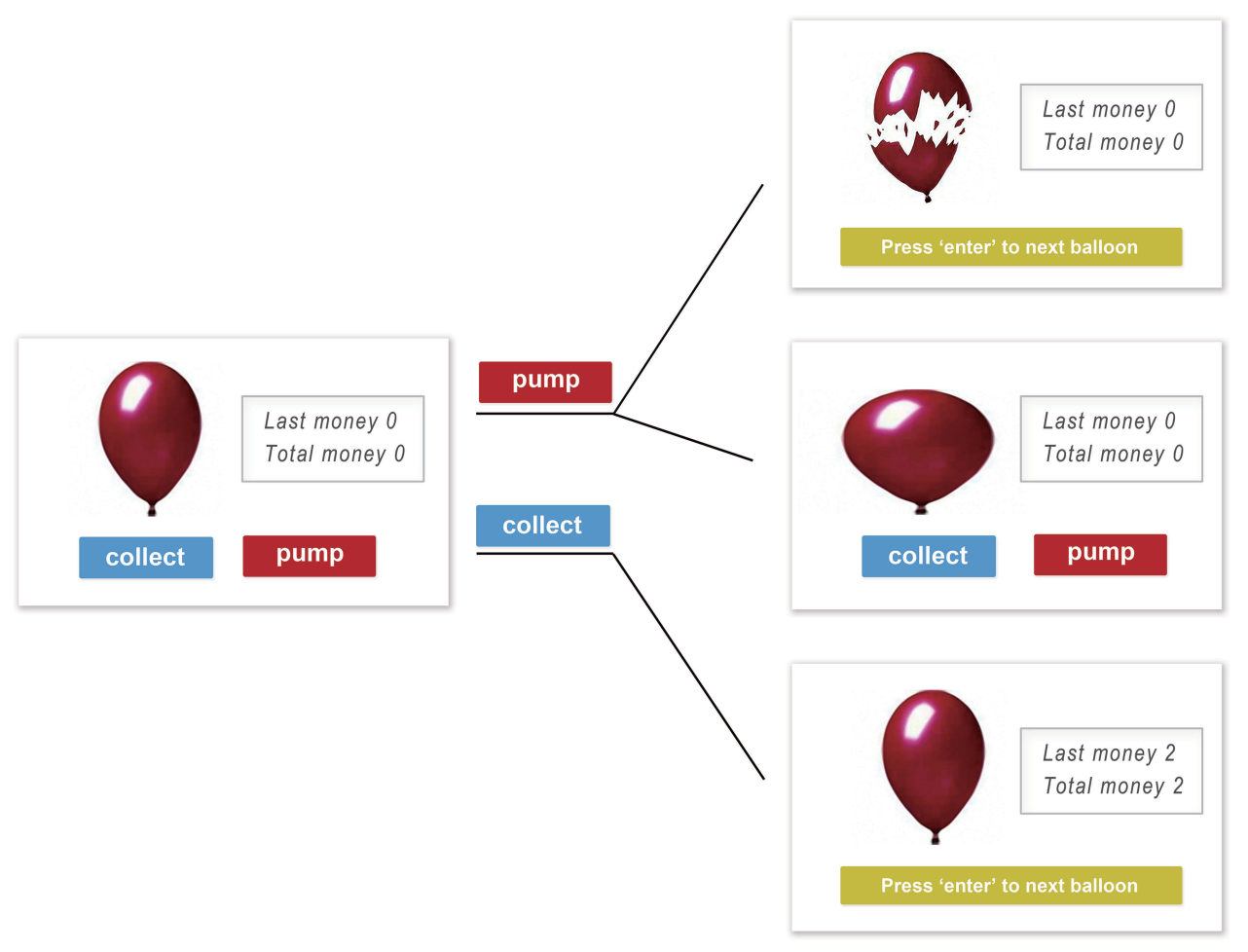

Figure I Balloon Analogue Risk Task (BART). 
Participants were instructed to pump 45 balloons and the task was self-paced. Considering the potential influence of fatigue (especially during the afternoon session) and keeping the similar duration with GNG task, the maximum number of inflation for each balloon was adapted to 16. Every 1 point could be earned by each successful pump and the explode threshold for each trial was determined randomly from a uniform distribution. Therefore, the probability of burst for a balloon on a given number of pumps is equal to "1/(16-number of pumps)". The reward value corresponding to each balloon and the total earning during the task were explicitly displayed, but the probability of explosion was blinded to participants. The indexes of this task include the adjusted average number of pumps (no bursted balloons), the number of explosive balloons, total gains, the average number of pumps of no bursted balloons immediately after a positive feedback (gain trial) or a negative feedback (loss trial).

\section{Go/No-Go Task (GNG)}

We applied the Go/no-go task to measure inhibitory control. In this task, participants were asked to respond as quickly as possible to the target stimuli ("go" stimuli), and to make no response to the non-target stimuli ("no-go" stimuli). There was a total of 120 trials in two test blocks during each test session (morning or afternoon), and each block included 45 go trials and 15 No-go trials. We used "A" and "O" as the stimuli, and these two letters as target stimuli and non-target stimuli alternately in the two blocks, respectively. The sequence of the two blocks was counterbalanced between participants and conditions (see Figure 2). There was a clear instruction before each test block about the Go and No-go letter. The indexes of the GNG task include mean reaction time of Go trials, hit rate (the number of correct hits on go trials), and false alarm rate (the number of incorrect hits on no-go trials).

\section{Subjective Sleepiness Rating and Objective Vigilant Performance}

We measured the subjective sleepiness and objective alerting performance to control the potential confounding influence of the sleepiness on risky decision making. To measure subjective sleepiness, we used the Karolinska Sleepiness Scale $(\mathrm{KSS})^{27}$ to evaluate participants' sleepiness from morning to afternoon. The KSS is a 1-item visual analogue scale, scored using a 10-point response range, from 1 (extreme alertness), to 5 (neither alertness nor sleepiness), to 10 (extreme sleepiness).

A 10-min version of the Psychomotor Vigilance Task $(\mathrm{PVT})^{28}$ was used to test the vigilance of participants in the present study. The PVT is sensitive to sleep loss and circadian rhythmicity $^{29,30}$ and free of practice effects. ${ }^{31,32}$ In this task, participants were asked to focus their attention on a red, rectangular box in the middle of a black screen, and to monitor that space for the appearance of a millisecond counter, which appeared at random intervals ranging from $2 \mathrm{~s}$ to $10 \mathrm{~s}$. They were instructed to stop the counter as soon as possible by pressing a specified button, after which they would be able to view their reaction time (see Figure 3). Participants were also instructed to avoid anticipating the stimuli so as not to register "false starts" or responses when no stimulus was present on the screen. The indexes of PVT included reaction time and number of lapses (reaction time longer than $500 \mathrm{~ms}$ ).

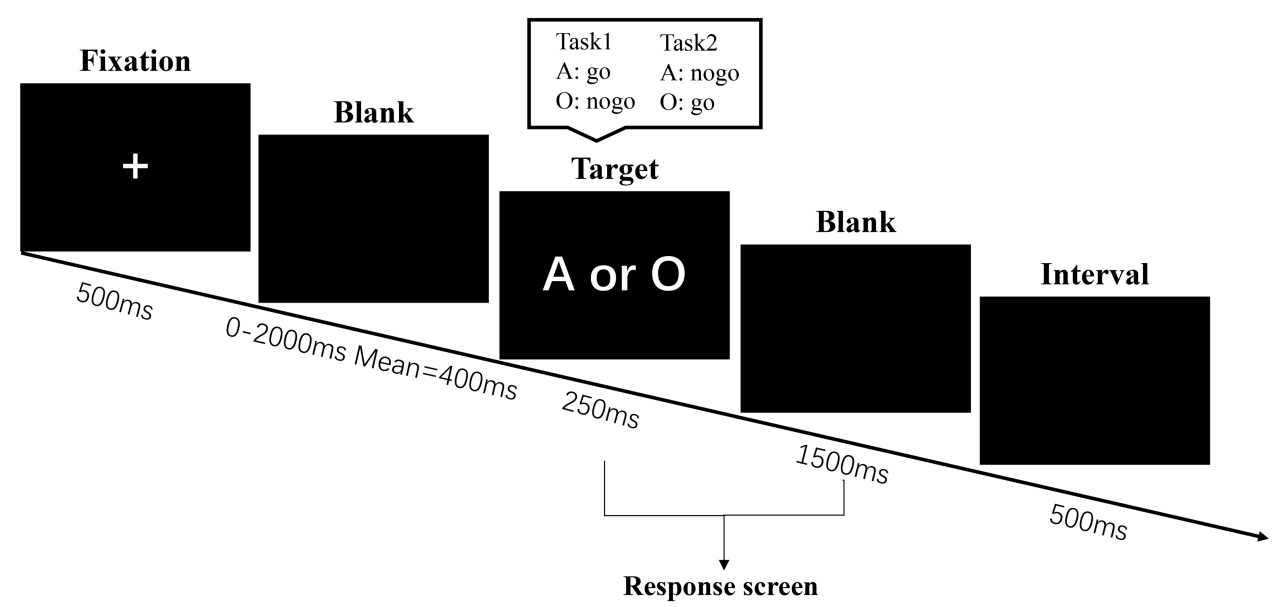

Figure 2 Go/no-go Task (GNG) task.

Note: The order of task I and task 2 was counter-balanced between different participants and sessions. 


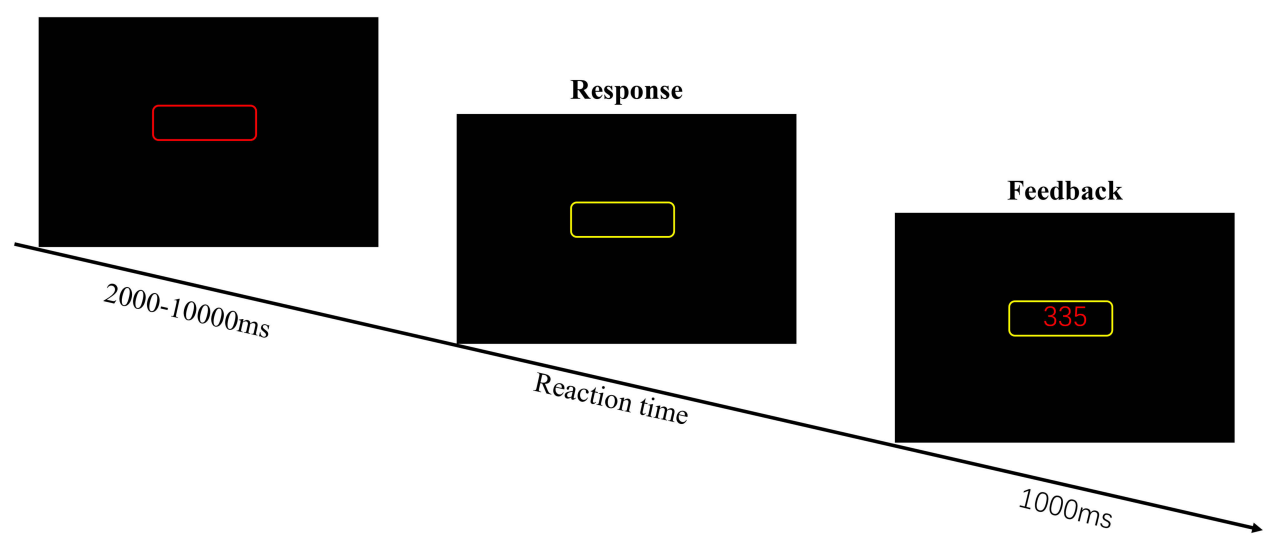

Figure 3 Psychomotor Vigilance Task (PVT) task.

\section{Experimental Procedure}

Participants arrived at the laboratory around 8:00 am to adapt to the environment of the lab for $1 \mathrm{~h}$. The laboratory was kept at a constant temperature $\left(26^{\circ} \mathrm{C}\right)$ and constant light (50 lux) to alleviate the confounding influences to on participants' circadian rhythm. ${ }^{4}$ Participants completed the Karolinska Sleepiness Scale, PVT, GNG task and BART twice, at 9 am and $3 \mathrm{pm}$, respectively (see Figure 4). As the 10-min PVT may induce mild fatigue, after the PVT, participants allowed to have 3-5 min rest before doing the GNG and BART tasks. Participants could not leave the laboratory, use smartphone/tablet, or nap at any time until they completed the whole experiment. Between the two testing sessions, participants were allowed to talk with the experimenters, read books, and to have lunch at 12:00 at noon. To control for other confounding factors, such as physical activity, the participants allowed to have limited activity in the lab. To avoid the learning effect of Go/No-go task, ${ }^{33}$ under the supervision of experimenters, participants practiced the
Go/No-go task for at least eight times on the two days prior to the experimental day in the same lab where the experiment conducted. The letters in the Go/No-go task during practice sessions were different with the letters during the experimental day. As suggested by White and colleagues, ${ }^{34}$ the BART has a good test-retest reliability across multiple test sessions. In our study, we provided the instructions for the BART to participants prior to the experiment day, and let them try a few trials to experience both win and loss with respect to pumping the balloons.

\section{Statistical Analysis}

Data were analyzed using SPSS 18.0 software for Windows. The Paired t-tests were performed to compare the time-of-day differences regarding the performances of the BART, PVT, GNG tasks, and the subjective sleepiness rating. The Pearson correlation was performed to explore the relationship between risk-taking behavior- and inhibitory control.

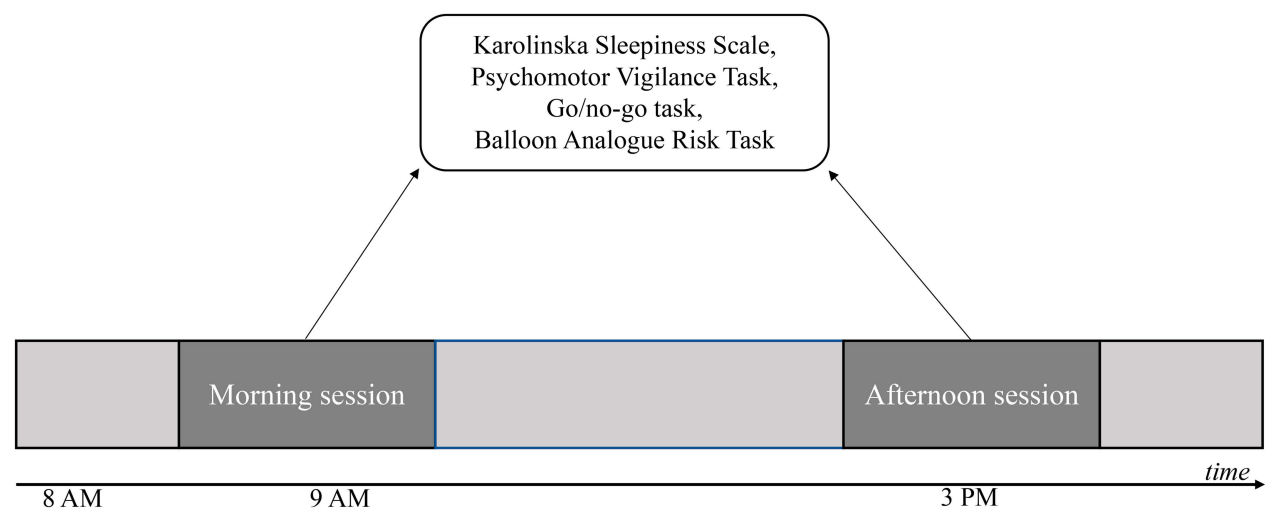

Figure 4 Experimental design and procedure. 
Table 2 Descriptive Statistics

\begin{tabular}{|c|c|c|c|c|c|}
\hline & $\begin{array}{l}\text { Morning } \\
(M \pm S D)\end{array}$ & $\begin{array}{l}\text { Afternoon } \\
(M \pm S D)\end{array}$ & t-value & p-value & Cohen's d \\
\hline \multicolumn{6}{|l|}{ BART } \\
\hline $\begin{array}{l}\text { Adjusted average number of pumps on unexploded } \\
\text { balloons }\end{array}$ & $6.06 \pm 1.16$ & $6.42 \pm 1.41$ & $-2.135^{*}$ & 0.042 & -0.404 \\
\hline Number of explosions (Loss number) & $17.36 \pm 3.73$ & $16.89 \pm 4.62$ & 0.762 & 0.453 & 0.144 \\
\hline Total gains & $164.00 \pm 18.10$ & $174.29 \pm 13.85$ & $-2.87 I^{* *}$ & 0.008 & -0.543 \\
\hline Negative feedback & $5.79 \pm 1.56$ & $6.24 \pm 1.68$ & $-2.74 I^{*}$ & 0.011 & -0.518 \\
\hline Positive feedback & $6.23 \pm 1.09$ & $6.48 \pm 1.36$ & -1.208 & 0.237 & -0.228 \\
\hline \multicolumn{6}{|l|}{ Go no-go } \\
\hline Go trials reaction time (ms) & $393.54 \pm 36.44$ & $391.25 \pm 36.02$ & 0.067 & 0.947 & 0.013 \\
\hline Go trials hit rate & $0.98 \pm 0.04$ & $0.99 \pm 0.02$ & -0.554 & 0.584 & -0.105 \\
\hline No-go trials false alarm rate & $0.13 \pm 0.09$ & $0.18 \pm 0.10$ & $-2.989 * *$ & 0.006 & -0.565 \\
\hline D prime & $3.53 \pm 0.59$ & $3.30 \pm 0.57$ & 1.977 & 0.058 & 0.374 \\
\hline \multicolumn{6}{|l|}{ Sleepiness and vigilance } \\
\hline Sleepiness & $4.93 \pm 1.21$ & $5.39 \pm 0.88$ & -1.904 & 0.068 & -0.360 \\
\hline PVT reaction time $(\mathrm{ms})$ & $332.13 \pm 21.61$ & $334.14 \pm 25.04$ & -0.577 & 0.569 & -0.109 \\
\hline PVT lapses & $2.75 \pm 2.46$ & $3.25 \pm 4.06$ & -1.070 & 0.294 & -0.202 \\
\hline
\end{tabular}

Note: ${ }^{*} p<0.05,{ }^{*} p<0.01$.

\section{Results}

The Time-of-Day Effects of Subjective Sleepiness and Objective Vigilant

\section{Performance}

There was no significant time-of-day effect with regard to both subjective sleepiness $(t(27)=-1.904, p=0.068$, Cohen's $d=-0.36$, see Table 2 ) and objective vigilance, as mean PVT reaction time $(t(27)=-0.577, p=0.569$, Cohen's $\mathrm{d}=-0.109)$, and the number of lapses $(t(27)=-1.07$, $p=0.294$, Cohen's $d=-0.202$, see Table 2).

\section{The Time-of-Day Effect of the Balloon Analogue Risk Task (BART)}

The paired $t$-test results showed significant time-of-day effects on the adjusted average number of pumps on unexploded balloons $(t(27)=-2.135, p=0.042$, Cohen's
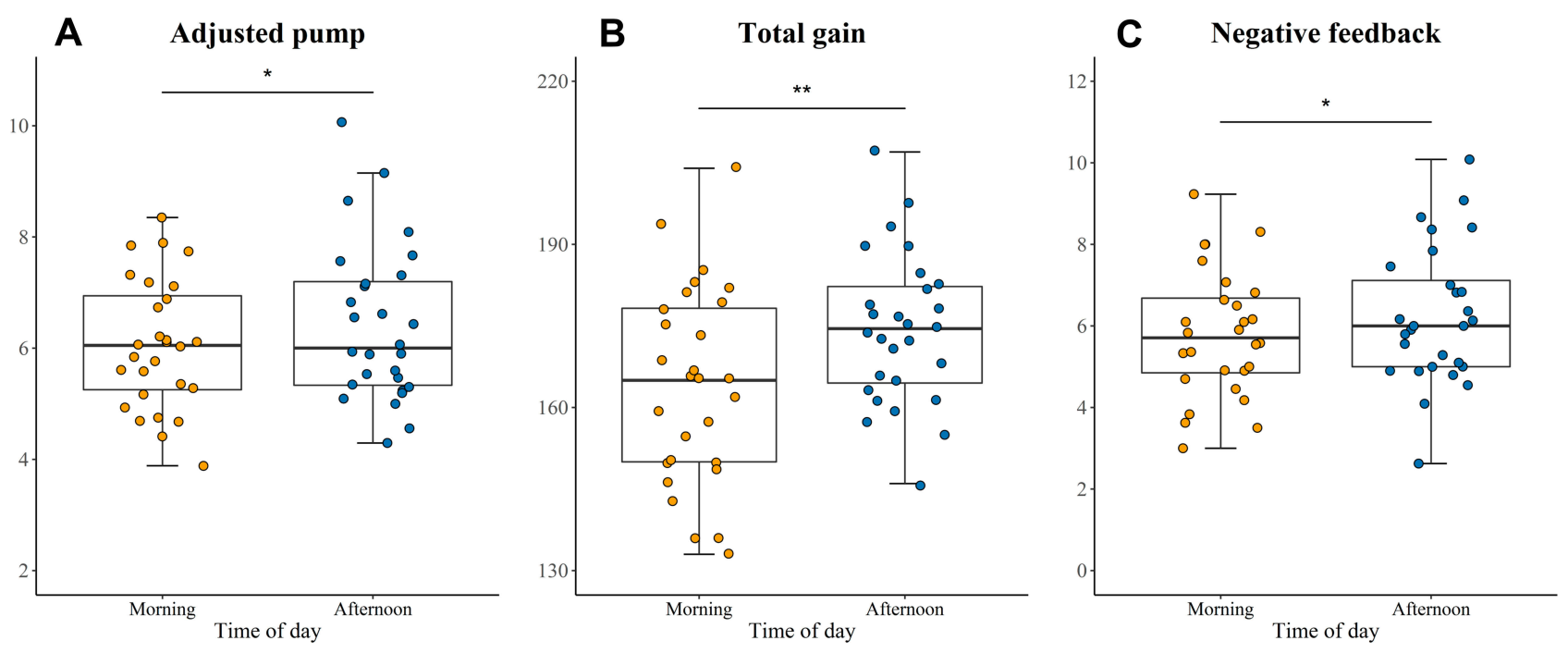

Figure 5 Time-of-day effect on Balloon Analogue Risk Task (BART). (A) The adjusted average number of pumps on unexploded balloons, (B) The total gains, (C) The adjusted average number of pumps after negative feedback. ${ }^{*} p<0.05, * * p<0.0$ I. 
$\mathrm{d}=-0.404$, see Table 2 and Figure 5A), and the adjusted average number of pumps on unexploded balloons in the afternoon $(\mathrm{M}=6.42, \mathrm{SD}=1.41)$ were significantly more than in the morning $(\mathrm{M}=6.06, \mathrm{SD}=1.16)$. There was also time-of-day effect on total gains $(t(27)=-2.871$, $p=0.008$, Cohen's $\mathrm{d}=-0.543$, see Table 2 and Figure 5B), participants got more in the afternoon $(\mathrm{M}=174.29, \quad \mathrm{SD}=13.85)$ relative to in the morning $(\mathrm{M}=164, \mathrm{SD}=18.1)$. However, there was no difference in the number of exploded balloons between the morning and afternoon sessions $(t(27)=0.762, p=0.453$, Cohen's $\mathrm{d}=0.144)$.

Furthermore, we calculated the average number of pumps after exploded balloons and unexploded balloons, representing the positive feedback condition (reactivity to wins) and the negative feedback condition (reactivity to losses) respectively. The paired $t$-test results showed significant time-of day-effects on the average number of unexploded pumps after negative feedback $(t(27)=-2.741$, $p=0.011$, Cohen's d $=-0.518$, see Table 2 and Figure 5C). The number of pumps was significantly higher in the afternoon $(\mathrm{M}=6.24, \mathrm{SD}=1.68)$ than in the morning $(\mathrm{M}=5.79$, $\mathrm{SD}=1.56$ ). However, no significant time-of-day effects were observed in relation to the positive feedback condition $(t(27)=-1.208, p=0.237$, Cohen's $\mathrm{d}=-0.228)$.

\section{The Time-of-Day Effect of Go/No-Go Task}

The paired $t$-test results showed no significant time-of-day effects on the reaction time and hit rate $(t(27)=-0.067$, $p=0.947$, Cohen's $\mathrm{d}=0.013 ; t(27)=-0.554, p=0.584$, Cohen's $d=-0.105$, see Table 2). The results for the false alarm rates did show significant differences between the morning and the afternoon sessions $(t(27)=-2.989$, $p=0.006$, Cohen's $d=-0.565$, see Table 2 and Figure 6), with the rate being lower in the afternoon $(\mathrm{M}=0.82$, $\mathrm{SD}=0.10)$ than in the morning $(\mathrm{M}=0.87, \mathrm{SD}=0.09)$. Additionally, we calculated d prime, an index of sensitivity discrimination that indicates the ability to distinguish signals (go trials) from noise (No go trials). However, the analysis did not reveal any significant time-of-day effects $(t(27)=1.977, p=0.058$, Cohen's $\mathrm{d}=0.374)$.

The relationship between risky decision making and inhibition control under the regulation of the time-of-day effects

We used the delta score ("the index score in the afternoon" minus "the index score in the morning") to measure the time-of-day effect of risky decision making

\section{No-go trials false alarm rate}

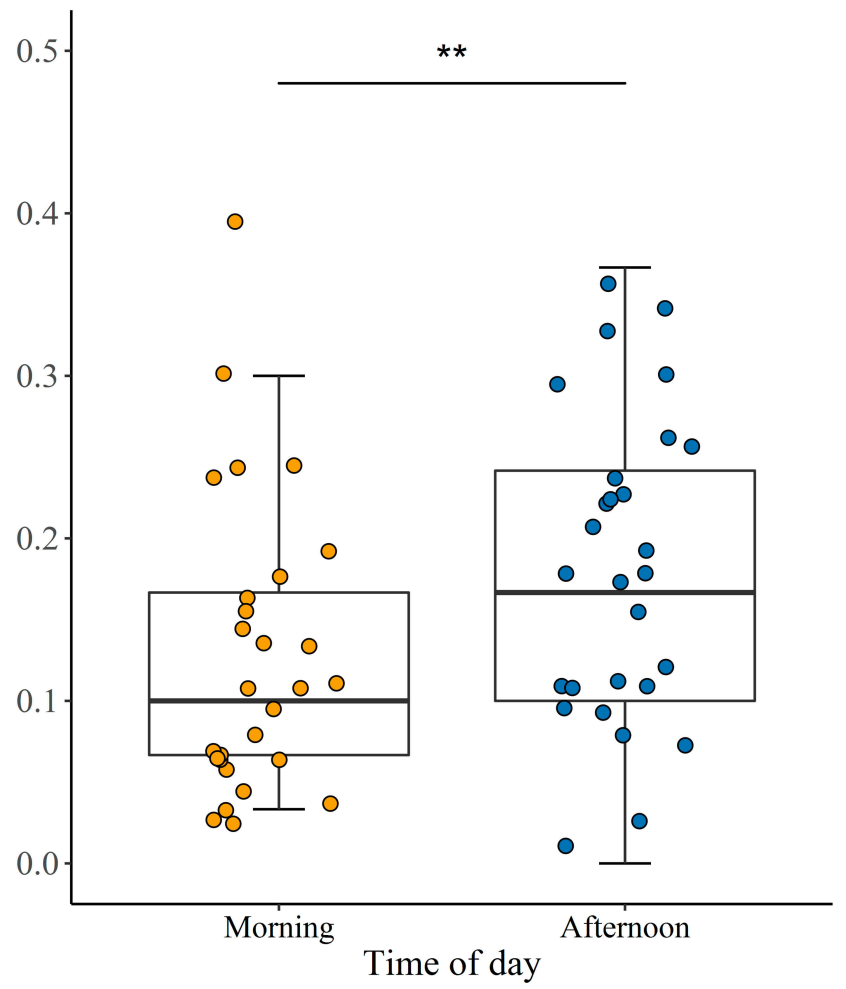

Figure 6 Time-of-day effect on No-go trials false rate which reflects the level of inhibitory control in Go/no-go task. ${ }^{* *} p<0.01$.

and inhibitory control. To explore the relationship between risky decision making and inhibitory control under the regulation of the time-of-day effects, we applied Pearson correlations to the delta score of the BART and Go/no-go task. The results showed that risky decision making was not correlated with inhibitory control (see Table 3).

\section{Discussion}

This study aimed to examine the time-of-day effect ( 9 am and $3 \mathrm{pm}$ ) on risky decision making (measured using the BART) and inhibitory control (measured using the Go/nogo task) simultaneously with intermediate chronotype individuals. In line with our hypothesis, participants performed higher risk propensity and insensitivity to negative feedback (loss) and showed lower inhibitory control in the afternoon. However, the results failed to reveal a significant correlation between the diurnal change of inhibitory control and risk-taking. The present study indicated that both risky decision making and inhibitory control are regulated by the time-of-day effect, but these two psychological processes may be relatively independent under the regulation of timeof-day. 
Table 3 The Correlation Between the Time-of-Day Effects on Risky Decision Making and Inhibitory Control

\begin{tabular}{|l|l|l|l|l|l|l|}
\hline Variables (Delta Scores) & $\mathbf{I}$ & $\mathbf{2}$ & $\mathbf{3}$ & $\mathbf{4}$ & $\mathbf{5}$ & $\mathbf{6}$ \\
\hline I. Adjusted average pumps & $\mathrm{I}$ & & & & & \\
2. Explosions & $0.727^{* * *}$ & $\mathrm{I}$ & & & & \\
3.Total gains & 0.209 & $-0.468^{* *}$ & 1 & & & \\
4.Positive feedback & $0.929^{* * *}$ & $0.735^{* * *}$ & 0.093 & & & \\
5.Negative feedback & $0.803^{* * *}$ & $0.543^{* *}$ & 0.245 & & & \\
6.No-go false alarm rate & -0.044 & -0.017 & 0.012 & 0.072 & $-0.429^{*}$ & 1 \\
7.D prime & 0.033 & -0.168 & 0.287 & 0.241 & $0.498^{* *}$ & $0.490^{* *}$ \\
\hline
\end{tabular}

Notes: The table showed no relationship between the change of BART (I-5) and other indexes (6-7) variation. Delta score = "index score in the afternoon" minus "index score in the morning"; Adjusted average pumps = Adjusted average number of pumps on unexploded balloons, Explosions $=$ Number of explosions, Negative feedback $=$ Average number of pumps after exploded balloons, Positive feedback $=$ Average number of pumps after the unexploded balloon. $* p<0.05, * * p<0.01, * * * p<0.00$ I.

According to the reinforcement sensitivity theory, the likelihood of risky behavior was modulated by the sensitivity to reward (gain) and punishment (loss). ${ }^{8}$ Generally, people were more sensitive to loss than reward. ${ }^{9}$ To examine this postulation in the context of the present study, we further explored the time-of-day effect on the feedback learning effect of risk-taking. The current results demonstrated that compared with in the morning, individuals pumped more times under the negative feedback condition in the afternoon, but no difference under the positive feedback condition. The higher number of pumps following negative feedback might reflect that individuals did not have the same level of sensitivity to loss in the afternoon as they did in the morning, and they might not make the risky decision based on the preceding feedback.

In line with our expectation, inhibitory control in the Go/no-go task was reduced when the risk propensity was higher in the afternoon. The findings were consistent with previous studies about the time-of-day effect on inhibitory control. ${ }^{35-37}$ Our results partially support the viewpoints of Yoon, ${ }^{10}$ that changes in cognitive function at off-peak time is due to impaired inhibitory control. Unfortunately, we did not find any significant relationship between the timeof-day effect on risky decision making and inhibitory control.

As Frings suggested, after prolonged waking times, people may desire greater gains but be increasingly insensitive to loss and be powerless to learn from previous experiences. ${ }^{38}$ This idea may suggest that the diurnal changes affecting risky decision making are related to increased sleepiness along prolonged waking times. However, our study did not find any significant differences in either the subjective sleepiness or objective PVT performance between the morning and the afternoon. Based on the current results, it seems that subjective sleepiness and objective vigilance do not influence risky decision making in the afternoon. However, future study is warranted to further explore this issue, because subjective sleepiness and objective performance may exist discrepancy under certain situations. ${ }^{29}$

Another explanation for the diurnal change of risktaking may be related to the influence of the reward system. According to a dual systems model of risktaking, the risk behavior is determined by two independent systems: the reward system and the cognitive control system. $^{39,40}$ Similar to cognitive control, reward function is also modulated by the time-of-day effects. A number of studies have demonstrated that the reward function is more active in the afternoon than at other times in one day. ${ }^{41,42}$ In the present study, individuals pumped more times in the afternoon, and even after the negative feedbacks. The current finding is consistent with the study of Byrne and Murray, suggesting that people seek more rewards due to the lower potential risk and higher potential reward in the afternoon. ${ }^{6}$ Therefore, the higher risk preference in the afternoon may be modulated by different levels of rewardseeking across a day.

\section{Limitation and Future Direction}

There are some limitations in the current study. First, the sample of the current study was relatively small. This may weaken the extent of the generalization with the present findings, even though the effect size of significant variables of BART and Go/no-go was acceptable. Future study may consider to use larger sample comprising morning and evening types, as well as intermediate types to examine the time-of-day effect on different cognitive functions. Second, participants completed all of the tests in one day. The morning session was consistently prior to the afternoon session, which may bring about practice effects. 
Although the previous study demonstrated the BART has adequate test-retest reliability, ${ }^{34}$ a counterbalanced order design with a larger sample of participants might help to verify the current findings. Third, we only selected two time-points with which to measure the performance of participants. It is difficult to demonstrate the variation of risk-taking in one day. In addition, the risky decision making showed a similar diurnal pattern compared with the reward function, which is at the peak in the afternoon than in the morning and evening. ${ }^{41}$ Future studies should adopt more time-points and combine risk-taking with reward seeking, for instance, measuring performance at 12-h phase differences to account for the circadian effects of risk taking. Finally, we only used behavioral tasks to measure the relationship between risky decision making and inhibitory control under the effect of time-of-day, which may hide the potential relevancy of risky decision making and inhibitory control. In the future, researchers may consider combining with neurophysiologic techniques, such as fMRI and EEG, to better explore the timeof-day effects on risky decision making and inhibitory control.

\section{Conclusion}

In the present study, we found that the time-of-day effect regulated risky decision making and inhibitory control. Individuals act with higher risk preference, less sensitivity to loss as negative feedback, and lower inhibitory control in the afternoon compared to in the morning. Furthermore, the alteration of risky decision making was not caused by the impaired inhibitory control in the afternoon, which suggests that the effects of time-ofday on risk propensity and inhibitory control may be relatively independent. Future studies may consider combining the reward function with neuroimaging methods to explore the diurnal variations of risky decision making. The current findings extend the understanding of the time-of-day effect on risky decision making and suggest that individuals may consider their optimal time when making an important decision since the time-of-day effect regulates decision-making behavior.

\section{Funding}

This work was supported by the Guangdong Basic and Applied Basic Research Foundation, China (No. 2019A1515012182).

\section{Disclosure}

The authors report no conflicts of interest in this work.

\section{References}

1. Blake MJ. Time of day effects on performance in a range of tasks. Psychon Sci. 1967;9(6):349-350. doi:10.3758/BF03327842

2. West R, Murphy KJ, Armilio ML, Craik FI, Stuss DT. Effects of time of day on age differences in working memory. J Gerontol B Psychol Sci Soc Sci. 2002;57(1):P3-10. doi:10.1093/geronb/57.1.P3

3. Schmidt C, Collette F, Cajochen C, Peigneux P. A time to think: circadian rhythms in human cognition. Cogn Neuropsychol. 2007;24 (7):755-789. doi:10.1080/02643290701754158

4. Goel N, Basner M, Rao H, Dinges DF. Circadian rhythms, sleep deprivation, and human performance. Prog Mol Biol Transl Sci. 2013;119:155-190. doi:10.1016/B978-0-12-396971-2.00007-5

5. Byrne JE, Murray G. Diurnal rhythms in psychological reward functioning in healthy young men: 'wanting', liking, and learning. Chronobiol Int. 2017;34(2):287-295. doi:10.1080/07420528.2016. 1272607

6. Ingram KK, Ay A, Kwon SB, et al. Molecular insights into chronotype and time-of-day effects on decision-making. Sci Rep. 2016;6:29392. doi:10.1038/srep29392

7. Schmitz F, Manske K, Preckel F, Wilhelm O. The multiple faces of risk-taking. Eur J Psychol Assess. 2016;32(1):17-38. doi:10.1027/ 1015-5759/a000335

8. Corr PJ. Reinforcement Sensitivity Theory (RST): introduction. In Corr PJ, editor. The Reinforcement Sensitivity Theory of Personality. New York: Cambridge University Press; 2008:1-43. doi:10.1017/ CBO9780511819384.002

9. Xu S, Fang Z, Rao H. Real or hypothetical monetary rewards modulates risk taking behavior. Acta Psychol Sin. 2013;45(8):874-886. doi:10.3724/sp.J.1041.2013.00874

10. Diamond A. Executive functions. Annu Rev Psychol. 2013;64:135-168. doi:10.1146/annurev-psych-113011-143750

11. Yoon C, May CP, Hasher L. Aging, circadian arousal patterns, and cognition. In: Park D, Schwartz N, editors. Cognitive Aging: A Primer. East Sussex: Psychology Press; 1998:151-170. doi:10. 4324/9780203345115

12. Kouchaki M, Smith IH. The morning morality effect: the influence of time of day on unethical behavior. Psychol Sci. 2014;25(1):95-102. doi:10.1177/0956797613498099

13. Wieth MB, Zacks RT. Time of day effects on problem solving: when the non-optimal is optimal. Think Reason. 2011;17(4):387-401. doi:10.1080/13546783.2011.625663

14. May CP, Hasher L, Foong N. Implicit memory, age, and time of day: paradoxical priming effects. Psychol Sci. 2005;16(2):96-100. doi:10.1111/j.0956-7976.2005.00788.x

15. Li Q, Nan W, Taxer J, Dai W, Zheng Y, Liu X. Problematic internet users show impaired inhibitory control and risk taking with losses: evidence from stop signal and mixed gambles tasks. Front Psychol. 2016;7:370. doi:10.3389/fpsyg.2016.00370

16. Yao YW, Wang LJ, Yip SW, et al. Impaired decision-making under risk is associated with gaming-specific inhibition deficits among college students with Internet gaming disorder. Psychiatry Res. 2015;229(1-2):302-309. doi:10.1016/j.psychres.2015.07.004

17. Noel X, Bechara A, Dan B, Hanak C, Verbanck P. Response inhibition deficit is involved in poor decision making under risk in nonamnesic individuals with alcoholism. Neuropsychology. 2007;21 (6):778-786. doi:10.1037/0894-4105.21.6.778

18. Telzer EH, Fuligni AJ, Lieberman MD, Galvan A. The effects of poor quality sleep on brain function and risk taking in adolescence. Neuroimage. 2013;71:275-283. doi:10.1016/j.neuroimage.2013.01. 025 
19. Lauriola M, Panno A, Levin IP, Lejuez CW. Individual differences in risky decision making: a meta-analysis of sensation seeking and impulsivity with the balloon analogue risk task. J Behav Decis Mak. 2014;27(1):20-36. doi:10.1002/bdm.1784

20. Lejuez CW, Read JP, Kahler CW, et al. Evaluation of a behavioral measure of risk taking: the Balloon Analogue Risk Task (BART). J Exp Psychol Appl. 2002;8(2):75-84. doi:10.1037//1076-898x.8.2.75

21. Ashenhurst JR, Bujarski S, Jentsch JD, Ray LA. Modeling behavioral reactivity to losses and rewards on the Balloon Analogue Risk Task (BART): moderation by alcohol problem severity. Exp Clin Psychopharmacol. 2014;22(4):298-306. doi:10.1037/a0036837

22. Donders FC. On the speed of mental processes. Acta Psychol (Amst). 1969;30:412-431. doi:10.1016/0001-6918(69)90065-1

23. Wessel JR. Prepotent motor activity and inhibitory control demands in different variants of the go/no-go paradigm. Psychophysiology. 2017;55(3):e12871. doi:10.1111/psyp.12871

24. Portaluppi F, Smolensky MH, Touitou Y. Ethics and methods for biological rhythm research on animals and human beings. Chronobiol Int. 2010;27:1911-1929. doi:10.3109/07420528.2010.516381

25. Horne JA, Ostberg OJ. A self-assessment questionnaire to determine morningness-eveningness in human circadian rhythms. Int J Chronobiol. 1976;4(2):97-110.

26. Kerkhof GA. Inter-individual differences in the human circadian system: a review. Biol Psychol. 1985;20:83-112. doi:10.1016/03010511(85)90019-5

27. Shahid A, Wilkinson K, Marcu S, Shapiro CM. Karolinska Sleepiness Scale (KSS). In: Shahid A, Wilkinson K, Marcu S, Shapiro CM, editors. STOP, THAT and One Hundred Other Sleep Scales. New York: Springer; 2011:209-210. doi:10.1007/978-1-44199893-4 47

28. Dinges DF, Pack F, Williams K, et al. Cumulative sleepiness, mood disturbance, and psychomotor vigilance performance decrements during a week of sleep restricted to 4-5 hours per night. Sleep. 1997;20 (4):267. doi:10.1093/sleep/20.4.267

29. Doran SM, Van Dongen HPA, Dinges DF. Sustained attention performance during sleep deprivation: evidence of state instability. Archives Italiennes de Biologie. 2001;139(3):253-267. doi:10.4449/ aib.v139i3.503

30. Dorrian J, Rogers N, Dinges DF. Psychomotor vigilance performance: neurocognitive assay sensitive to sleep loss. In: Kushida CA, editor. Sleep Deprivation. Boca Raton: CRC Press; 2004:39-70. doi:10.3109/9780203998007-4
31. Basner M, Dinges DF. Maximizing sensitivity of the psychomotor vigilance test (PVT) to sleep loss. Sleep. 2011;34(5):581-591. doi:10.1093/sleep/34.5.581

32. Basner M, Hermosillo E, Nasrini J, et al. Repeated administration effects on psychomotor vigilance test performance. Sleep. 2018;41 (1):zsx 187. doi:10.1093/sleep/zsx 187

33. Schapkin SA, Falkenstein M, Marks A, Griefahn B. Practice-related effects in a go-nogo task. Percept Mot Skills. 2007;105(3):1275-1288. doi:10.2466/PMS.105.7.1275-1288

34. White TL, Lejuez CW, de Wit H. Test-retest characteristics of the Balloon Analogue Risk Task (BART). Exp Clin Psychopharmacol. 2008;16(6):565-570. doi:10.1037/a0014083

35. García A, Ramírez C, Martínez B, Valdez P. Circadian rhythms in two components of executive functions: cognitive inhibition and flexibility. Biol Rhythm Res. 2012;43(1):49-63. doi:10.1080/ 09291016.2011 .638137

36. Hartley LR, Shirley E. Color-name interference at different times of day. J Appl Psychol. 1976;61(7):119-122. doi:10.1037//0021-9010. 61.1 .119

37. Manly T, Lewis GH, Robertson IH, Watson PC, Datta A. Coffee in the cornflakes: time-of-day as a modulator of executive response control. Neuropsychologia. 2002;40(1):1-6. doi:10.1016/s00283932(01)00086-0

38. Frings D. The effects of sleep debt on risk perception, risk attraction and betting behavior during a blackjack style gambling task. J Gambl Stud. 2012;28(3):393-403. doi:10.1007/s10899-011-9266-9

39. Humphrey G, Dumontheil I. Development of risk-taking, perspective-taking, and inhibitory control during adolescence. Dev Neuropsychol. 2016;41(1-2):59-76. doi:10.1080/87565641.2016.116 1764

40. Steinberg L. A dual systems model of adolescent risk-taking. Dev Psychobiol. 2010;52(3):216-224. doi:10.1002/dev.20445

41. Byrne JEM, Hughes ME, Rossell SL, Johnson SL, Murray G. Time of day differences in neural reward functioning in healthy young men. J Neurosci. 2017;37(37):8895-8900. doi:10.1523/JNEUROSCI. 0918-17.2017

42. Hasler BP, Forbes EE, Franzen PL. Time-of-day differences and short-term stability of the neural response to monetary reward: a pilot study. Psychiatry Res. 2014;224(1):22-27. doi:10.1016/j. pscychresns.2014.07.005
Nature and Science of Sleep

\section{Publish your work in this journal}

Nature and Science of Sleep is an international, peer-reviewed, open access journal covering all aspects of sleep science and sleep medicine, including the neurophysiology and functions of sleep, the genetics of sleep, sleep and society, biological rhythms, dreaming, sleep disorders and therapy, and strategies to optimize healthy sleep.
The manuscript management system is completely online and includes a very quick and fair peer-review system, which is all easy to use. Visit http://www.dovepress.com/testimonials.php to read real quotes from published authors. 